\title{
OPPORTUNITIES AND CHALLENGES IN THE SALE OF AGRICULTURAL PRODUCTS FROM SMALL AND FAMILY FARMS IN BULGARIA
}

\author{
M. Nikolova \\ Department "Agrarian Economics", D. A. Tsenov Academy of Economics, \\ Svishtov, Bulgaria,
}

\begin{abstract}
Foods are a natural necessity for sustaining the life of the human body. Therefore, it is important for each person to be able to meet their needs, depending on their individual diet. There are more and more people who prefer Bulgarian products on their table. Many consumers are looking for quality and healthy products through direct contact with producers in the region, in farmers' markets, but also in large food chains. The problem is that products from small and family farms can hardly reach the stands in food chains, where most of the products offered are still of foreign origin. The purpose of our study is related to the study of the possibilities for realization of agricultural products from small and family farms in Bulgaria. The research methods used in the study include: general research methods, survey, summary and synthesis, logical method, tabular, graphical and schematic presentation of characteristics and trends. The results of the research can be systematized in several directions: the answers for solving the problems of small agricultural farms, related to the successful realization of their seasonal production, are sought; the need for greater support for small farms in each region is revealed. In this regard, the role of all stakeholders in the chain, incl. and the need for active implementation of both state tools and the assistance of local authorities on a regional scale. In conclusion, measures to improve the supply chain of agricultural products from small farms must be aimed at strong horizontal and vertical integration between key figures in the sector. The state national policy for increasing the competitiveness of small and family farms must constantly follow the focus on small farmers, who find it difficult to sell products in general and even more so in emergency situations. Greater support for small farms in each region is more than needed.
\end{abstract}

Key words: potential, realization, agricultural products, market access, national support policy, regional development

\section{INTRODUCTION}

The development and functioning of the local food markets is a favorable opportunity to strengthen the market position of agricultural holdings, especially small ones, and to ensure the supply of sufficient quality food to Bulgarian consumers. In the modern conditions of the development of Bulgarian agriculture, the goal of the functioning farmers' markets is to achieve a common cause in favor not only of farmers from specific settlements but also to meet the demand for quality and healthy products of authentic, local origin. Subsidies are a powerful tool, and the role of the state is regulatory, i.e. to stimulate processing, added value, job creation, family farms, development of the region, etc.
In the conditions of market economy, without a successful realization of the produced foods it is unthinkable sustainable development and good results of the activity. In this regard, our study focuses on the study of the potential of small farms for the sale of products, as well as their institutional support to strengthen their position in the regional scope. Good partnerships between producers, depending on their production direction (vegetables, essential oils, fruits, etc.) create regional competitive advantages and opportunities for positioning and entering not only local markets but also large retail chains. Inevitably, the role of state support for the start-up and development of small farms is also important, which undoubtedly leads to a comprehensive 
strengthening of the socio-economic situation in the region, as well as improving the quality of life.

After the 1990s, the institutional framework of agriculture underwent a structural transformation. In-depth studies of the main actions needed to avoid negative fluctuations in agribusiness development as a result of the structural transformation of the institutional framework of agriculture and the adaptation of organizational structures to dynamic changes in the market environment are needed (1). According to Nikolova, M. and M. Linkova in the mentioned publication, when studying the fluctuations in the management and development of agriculture it was established that some of the reasons are related to limited access to the market of small agricultural holdings; low level, but horizontal and vertical integration; need for effective and sustainable management of land resources, etc.

Despite the wide discussion of the problems and challenges facing small and family farms, at this stage effective mechanisms for their more active role in European agriculture have not yet been implemented, and this necessitates further research in this direction.

\section{MATERIAL AND METHODS}

The research methods used in the study include: general research methods, survey, summary and synthesis, logical method, graphical representation of characteristics and trends. The survey was conducted in the period January-May 2020, covering questions about the sale of manufactured raw materials and products. The purpose of the study is related to the study of the opportunities and challenges for successful realization of the products produced by small and family farms. The objectives of the study include revealing the potential of small farms for the sale of agricultural products, as well as outlining the institutional support for their development in achieving sustainability. On this basis, conclusions and recommendations are made regarding the possibilities for increasing and stabilizing the sustainability of small and family farms. In order to achieve the formulated goal, the main factors for revealing the potential of small and family farms, the main channels for distribution of products from small and family farms, the state national policy for increasing the competitiveness of small and family farms are monitored.

\section{RESULTS AND DISCUSSION}

Potential of small agricultural holdings for realization of the produced production. The problems related to the sale of products from small and family farms are a long-standing case in agricultural practice. The value of their production increases further due to unique sought-after characteristics, such as taste, unique aroma, local identity, personal preferences, etc. More and more consumers are looking for Bulgarian products in large retail chains, in local markets or directly from regional farmers.

In the general sense, food products that are a natural necessity for maintaining the life of the human body are products, ie. foods that are consumed by people in the process of eating, depending on individual diets and preferences of individuals. According to Regulation (EC) № 178/2002 of the European Parliament and of the Council (2), the term "foodstuffs" (or "foodstuffs") means any substance or product, whether processed or not, partially processed or unprocessed, which is intended for or reasonably expected to be accepted by humans. This definition is also transferred to the Bulgarian legislation and more precisely to the Food Act (3), where it says "food is any substance or product that is intended or can be used for human consumption, regardless of whether it is processed, partially processed or unprocessed.

The role of small and family farms in Bulgaria in the sale of products of high quality and high nutritional value is undoubtedly important, especially in the regional scope. Their potential is largely untapped due to a number of concomitant problems. The adaptation of small business to modern conditions is an important part of the ability to be competitive compared to other companies, to attract investment, to modernize and diversify its activities. Small and medium-sized businesses occupy an indisputable share in the economy of our country in terms of production capacity, employment, innovation potential and opportunities to increase their competitiveness. The fact is that small companies are directing their business to local markets, as a result of which they are part of regional fluctuations. The main difficulties are related to the creation and development of low-income environments, especially in backward rural areas. Very often these companies have limited potential to generate added value, but in times of crisis the 
business is oriented towards fast-moving activities. On the other hand, the Bulgarian economy has great potential for the development of small business with increasing investment activity of owners through various direct investments. And this inevitably leads to increased employment and more effective job restructuring.
Farmers in our country register and provide information about their activities in a special register, according to the requirements of Ordinance 3/1999 (4). The data is constantly updated and provides accurate information about the current situation in our country. In Figure 1 presents the changes in the number of farmers during the different economic years, for the period $2012-2019$.

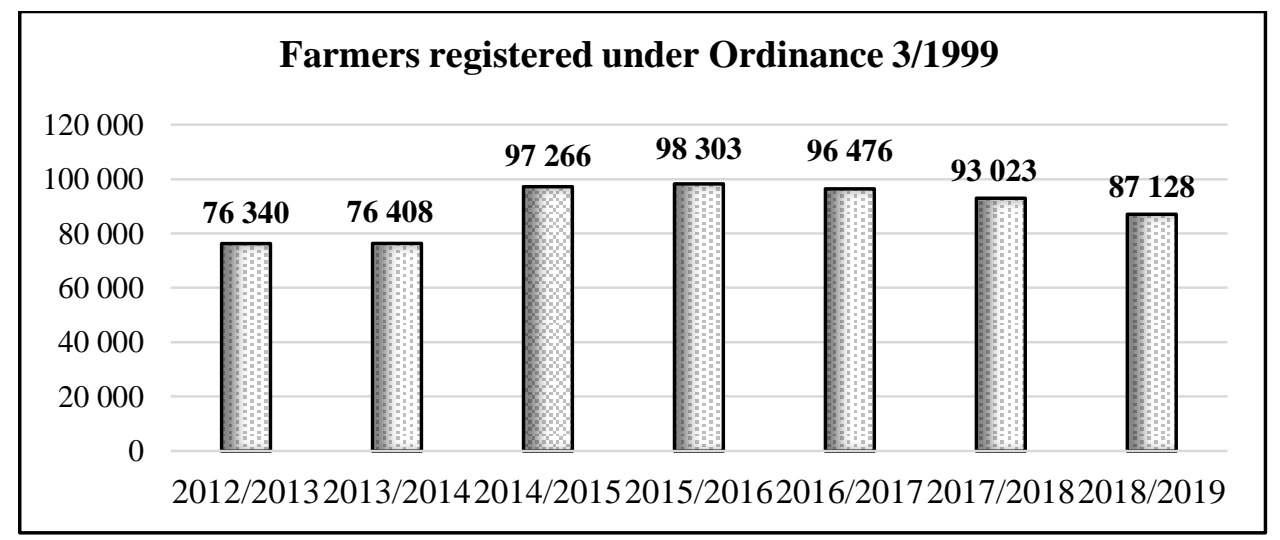

Figure 1. Total number of registered farmers

Source: MAFWE, Annual Report on the State and Development of Agriculture (5)

In recent years, the total number of farmers registered under Ordinance № 3/1999 has been declining alarmingly. For the business year $2017 / 2018$ their number is 93023 , and as of July 2019 - 87128 , i.e. by 5,895 less. There is a steady downward trend in the number of farmers. The processes related to the reduction of the number of farms are most dynamic in small and small agricultural holdings.

The main factors in small and family farms in Bulgaria, which are the basis for revealing their full potential, can be systematized as follows:

- strong polarization in structural terms;

- age of employees;
- the need to attract young farmers.

According to Eurostat data, the average size of farms in 2016 increased from 6.2 ha to 20.6 ha (Figure 2). This shows a significant increase due to the natural process of reducing them and increasing the utilized agricultural area (UAA). This fact can be reported as a result of the effect of direct payments under the Rural Development Program (RDP), which in itself leads to increased motivation on the part of farmers to consolidate agricultural holdings. The structural changes for the period after our accession to the EU and the support under the first pillar of the RDP find expression and outline this trend.

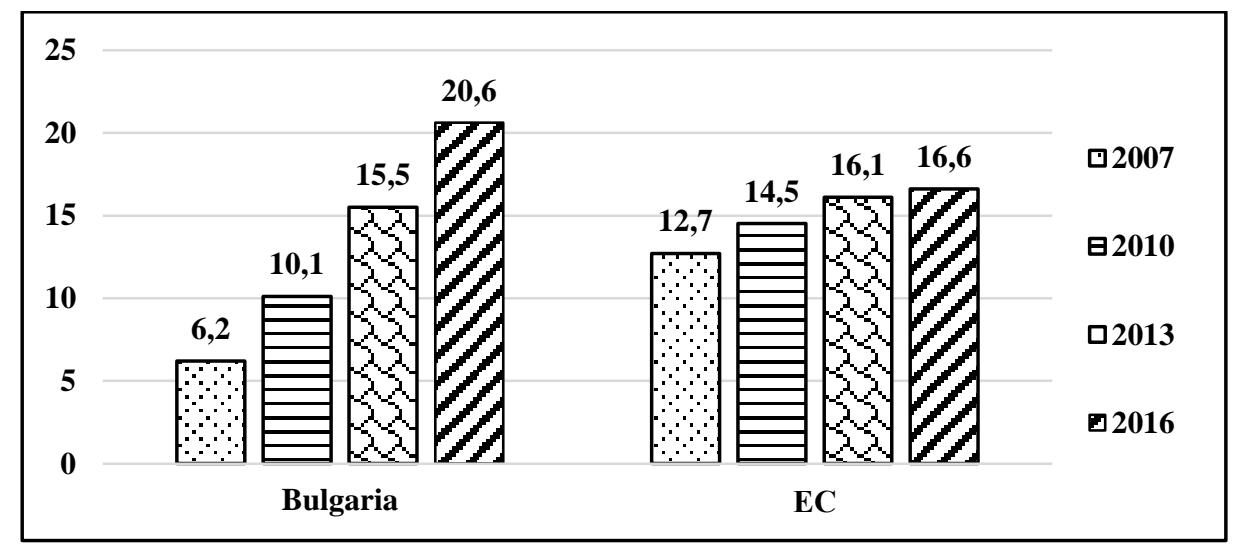

Figure 2. Average size of agricultural holdings, ha

Source: Eurostat 
A study by the Institute of Agrarian Economics found that Bulgaria is characterized by maintaining an irrational organizational and economic structure of agriculture - a dominant share of small and small farms of individuals and a small number of large business structures of legal entities. A significant number of medium-sized agricultural holdings are still missing. At one pole are small and small farms with UAA size up to 2 ha, in which more than half of the labor input in the industry is concentrated, but they manage only $1.8 \%$ of UAA in the country. At the other pole are the largest farms, which in 2016 accounted for less than $5 \%$ of farms, with a share of labor $-20 \%$ and manage over $85 \%$ of the total UAA in the country (6). The analysis shows that despite the positive trends in the restructuring, the strongly dualistic organizational and economic structure in Bulgarian agriculture is preserved and a significant layer of medium-sized agricultural holdings is still missing.

In Bulgaria, the polarization and formation of bipolar agriculture (large and very small farms) is increasingly expressed, with $1.5 \%$ of them managing $82 \%$ of arable land for growing five cereals and oilseeds (wheat, barley, corn, sunflower and rapeseed) (7).

The comparative analysis for the period 20072016 shows a significant difference in the average sizes by groups of farms, which is preserved for the whole analyzed period (Figure 3). The data show: insignificant change in the average size of farms up to 10 ha; increase of the average size of the farms from $10-50$ ha; reduction of the average size of farms over 50 ha. At the end of the analyzed period, the average size of small farms is 0.5 ha, while the largest is immeasurably larger 340.5 ha.

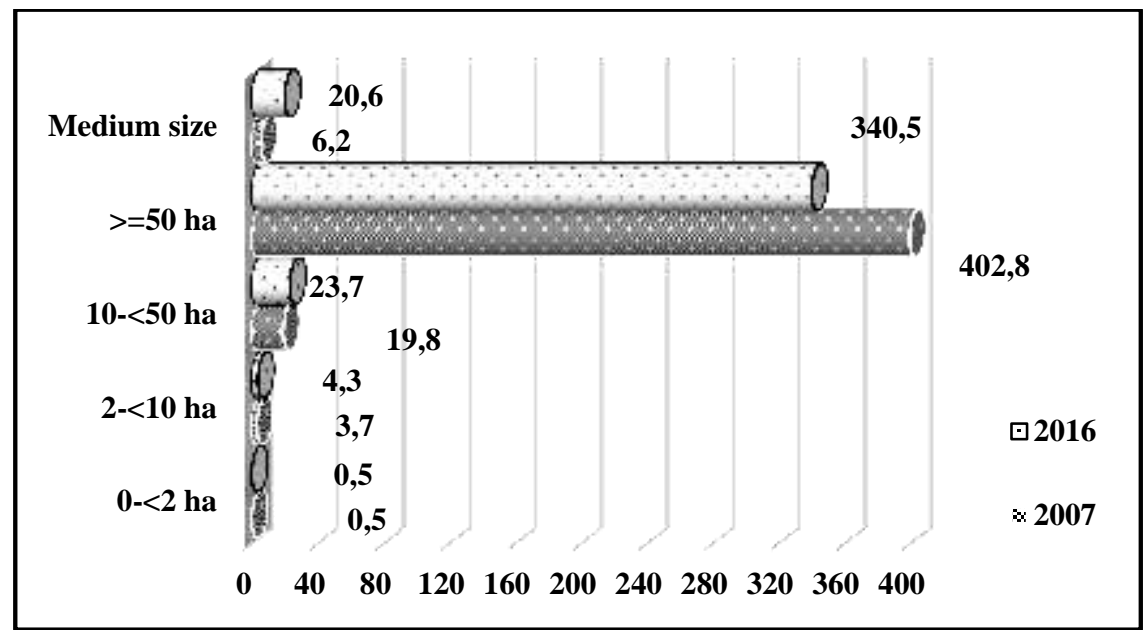

Figure 3. Dynamics in the average size of agricultural holdings by groups, ha Source: Eurostat

The age of farmers is also an important issue in the agricultural sector. Still persons over or over 65 years of age, investing labor and time for the development of agricultural holdings predominate - 123,054 in number. According to Eurostat (2016), about 36 percent or more than a third of Bulgarian farmers are aged 65 and over. About half of the people in our country who are engaged in agriculture or other agricultural activities are aged 40-65, and the number of young farmers in our country is only 14 percent. The two main measures operating in the old and the current reference period (2007-2013 and 2014-2020) have the greatest impact on attracting young people in the agricultural sector and they are:

measure 112 "Establishment of farms for young farmers" $\checkmark \quad$ sub-measure 6.1 "Start-up aid for young farmers"

These are the measures that contribute to the manifestation of the effects of the RDP and the dynamics in the number - from 2566 in 2009 to 7 051 young farmers in 2016 (Figure 4). They are the innovative entrepreneurs with entrepreneurial initiatives in the agricultural sector. Generational change is one of the fundamental elements for the long-term adaptability or flexibility of agricultural systems. Therefore, their role is especially important for the development of individual regions, which are characterized by specific characteristics - organizational and demographic, established production practices, specific local natural, institutional and infrastructural conditions. 


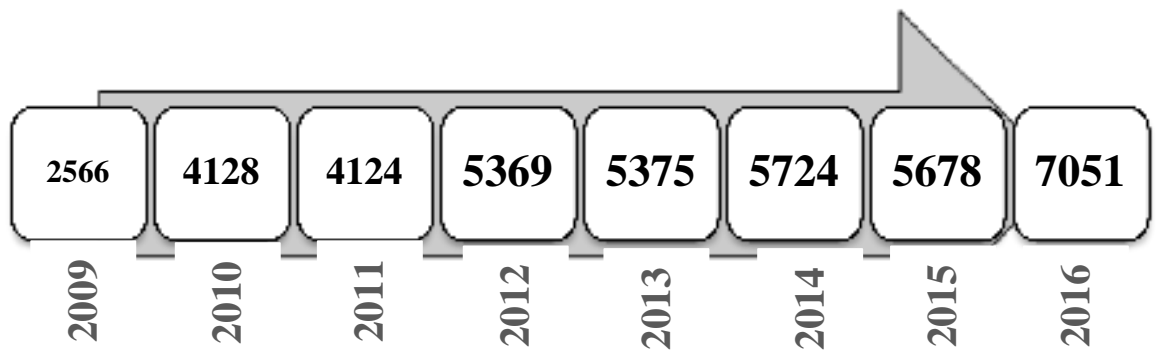

Figure 4. Young farmers in BuIgaria Ior tne period $\angle U U Y$ - LU10, number

Source: author's figure according to data from the Institute of Agrarian Economics

The positive trend of involving young people who are highly motivated and aware of the possibility of development in a still unoccupied entrepreneurial niche with untapped potential.
From their distribution by statistical regions in Table 1 shows that their share for the first three groups $(<=24,25-34,35-44)$ is the largest in the South Central region.

Table 1. Persons working in agricultural holdings- by sex and age by statistical regions (Number of persons)

\begin{tabular}{|c|c|c|c|c|c|c|c|c|}
\hline \multirow{3}{*}{$\begin{array}{l}\text { Statistical } \\
\text { regions }\end{array}$} & \multicolumn{8}{|c|}{ Persons working in agricultural holdings } \\
\hline & \multicolumn{2}{|c|}{ Sex } & \multicolumn{6}{|c|}{ Age groups (years) } \\
\hline & men & women & $<=24$ & $25-34$ & $35-44$ & $45-54$ & $55-64$ & $>=65$ \\
\hline BULGARIA & 264393 & 175343 & 7050 & 33473 & 67157 & 100989 & 108012 & 123054 \\
\hline Severozapaden & 30183 & 17318 & 827 & 3547 & 7013 & 10275 & 10396 & 15443 \\
\hline Severen tsentralen & 35016 & 19165 & 1080 & 4958 & 8765 & 14653 & 11551 & 13174 \\
\hline Severoiztochen & 31983 & 17313 & 975 & 3697 & 9002 & 12434 & 11928 & 11262 \\
\hline Yugoiztochen & 38313 & 23101 & 1000 & 5672 & 10363 & 13496 & 15074 & 15809 \\
\hline Yugozapaden & 49758 & 37469 & 1100 & 6186 & 11705 & 18289 & 20551 & 29397 \\
\hline Yuzhen tsentralen & 79140 & 60977 & 2068 & 9413 & 20309 & 31843 & 38513 & 37970 \\
\hline
\end{tabular}

The market access of the predominant number of small farms is limited, and it is they who provide the variety of good quality agricultural products at affordable prices. This further deepens the structural and territorial asymmetries in the development of Bulgarian agriculture. Data from Infostat from 2019 (8) show that for ten years the South Central region has been significantly behind the leader in the production of agricultural products, especially vegetable production, fruit growing, viticulture, with a decrease of more than half a billion levs.

Sales of agricultural products from small and family farms in Bulgaria. Increasingly worldwide and more and more governments around the world are beginning to realize the role and importance of family farms as a major factor in conserving and conserving local resources. It is no coincidence that the United Nations General Assembly has declared 2014 the Year of Family Agriculture. The main goal of the initiative is to promote, strengthen, develop and maintain family farming in all areas - crop production, animal husbandry, fisheries and forestry, as a socially valuable, culturally acceptable, economically viable, environmentally sustainable and politically relevant system in different countries and regions around the world (9). In recent decades, family farming is most often defined as the main primary form of organization in agriculture, in which the farmer assumes the risk of production and sale of products and together with his family performs all (or part) of agricultural work and management functions (10).

Due to the huge scale of family farming in the EU, ensuring a constant supply of high quality and diverse products, family farmers in the EU contribute to food security at regional, national and European level. Family farms also contribute to the sustainable ecological development of agricultural systems. There are several factors that prove that family farms can provide a higher standard of care for the 
environment than non-family farming (11): small and semi-subsistence farms are more likely to engage in mixed farming, take advantage of better and recycle nutrients within the farm; in most cases they apply traditional technologies that are environmentally friendly; small farms usually cultivate smaller plots, easily carry out crop rotation, use soil-sparing methods for its cultivation; family farming is more likely to have long-term environmental goals.

For successful realization of the produced production, with the main goal of achieving sustainability in the development of the family business, it is possible to adapt to the environment depending on the changes not only in the market environment, but also changes in consumer attitudes for certain goods or services. A competitive advantage is the desire to conquer unoccupied entrepreneurial niches, the use of technological innovations or the inclusion of environmentally friendly practices in the development of the organization. For example, some of the family businesses are related to entrepreneurial ideas in which profit generation is the goal and eco-innovation is the means to achieve it. For others, on the other hand, the ecological mission is a goal and the generation of profits is a means. In the first case we have an established market and a new product for it, therefore the business organization gains a competitive advantage due to eco-innovation (for example, the successful meat processing company "Tandem" started its activity as a family business by the brothers Kiril and Todor Vatevi (1993). They started production of meat products in a building for rent, which bought old cars with a mortgage loan, two Trabant cars. They want to produce only products that everyone would feed their children. They constantly strive to apply innovations and so in 2013 they included the production of organic products, and in 2014 "Organic pork fillet" of Tandem were chosen by consumers as a favorite product in the category "Organic products"). In the second case, the goal is to change attitudes and suggest / create a need, and therefore - the market demand for a particular type of product, which alternatively becomes a mass trend (for example, the various natural and organic products that are increasingly preferred and sought after by certain target groups of people. They have motivated both entrepreneurial initiatives when starting a family business). In both cases, however, the environmental mission is an element of the identity and core values of the family business and rather of the strategic guidelines in the management of the organization. Of course, the priorities of different business structures are different and it all depends on the promoters of change. In the family business, these are people who are members of the family and are usually younger, more educated, with technological capabilities, with competencies in the field of development to target, regardless of product or technological innovation and others. Advantages / qualities related to effective management of the business organization.

When the question of the market orientation of the farms is raised, the question of the channels of realization of the production is also important. In order to overcome unfair competition, dependence on wholesalers and resellers, short supply chains are extremely important. For the analyzed period a slight increase in the share of agricultural holdings was found, whose sales directly to the consumer exceeded half of the total sales volume - from $16.9 \%$ in 2007 to $18.7 \%$ in 2016 (2). To improve the functioning of food chains and stimulate the construction of short food chains, it is necessary to develop market structures and create normal market relations in agriculture: completion of market structures (exchanges, markets, warehouses and refrigeration facilities) on a regional basis; stimulating the production of quality products; elimination of competition from the informal sector and illegal imports; farmers' association. The main channels for distribution of products from small and family farms are:

- farmers' regional markets;

- online realization;

- large retail chains.

In recent years, farmers' markets are characterized by great consumer interest and a sought-after place for direct contact in the food chain for the supply of fresh products of Bulgarian origin. The development and functioning of local farmers' markets (12) in different regions of Bulgaria show that this form of realization is increasingly preferred by consumers, as an opportunity for direct communication and guaranteed quality. We are all convinced that the development of local food markets is a favorable opportunity to strengthen the market position of agricultural 
holdings, especially small ones, and ensure the supply of sufficient quality local food to Bulgarian consumers. And especially the implementation of short supply chains and the functioning of a real market, where the demand of the modern consumer meets the supply of quality products "on a regional scale. The fact is that in other countries about $15 \%$ of all farms process and sell some or all of their products directly, while in Bulgaria they are much less. In the modern conditions of the development of Bulgarian agriculture, the goal of the functioning farmers' markets is to achieve a common cause in favor not only of farmers from specific settlements, but also to

meet the demand for quality and healthy products of authentic, local origin.

According to the surveyed farmers from Veliko Tarnovo region, the question "What domestic markets do you use for sale" (Figure 5) is mostly represented by the opinions for the sale of manufactured products through direct sales and markets of producers (local farmers / regional markets). The preferences for realization are the lowest, by offering in wholesale markets and in retail stores. Intermediate position is occupied by the realization, through online deliveries, contracts to companies / retail chains or with individuals, as well as the supply in the chains of restaurants and hotels.

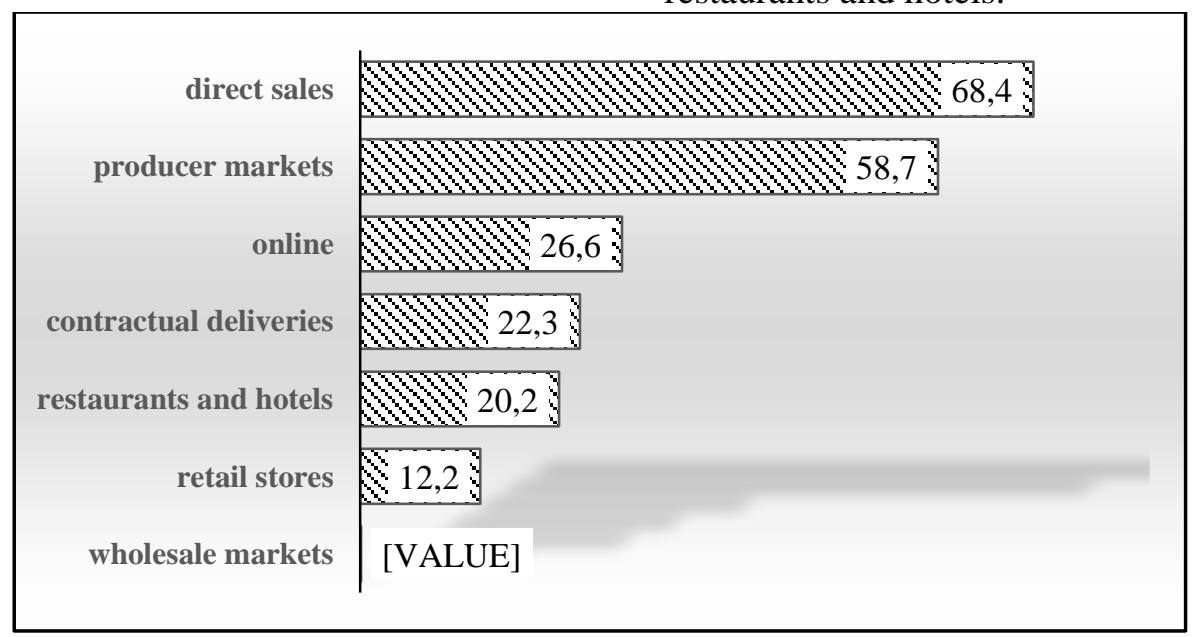

Figure 5. Extent of use of domestic markets for product sales

Retail chains are those that apply unfair trade practices and worsen the position of Bulgarian farmers in the value chain and the relations between economic entities. A survey conducted by the Institute of Agrarian Economics with representatives of industry associations found that unfair trade practices seriously increase the cost of sales, have a significant negative effect on business planning and impose the sale of products to farmers in most agricultural sectors. at prices below cost.

The state national policy for increasing the competitiveness of small and family farms. To implement the measures and achieve the goals of the agricultural policy in 2019, a set of instruments for financial support with European and national funds is applied. This includes mainly direct payments and market support under the first pillar of the Common Agricultural Policy (CAP), financed by the European Agricultural Guarantee Fund and the implementation of the measures of the Rural
Development Program (RDP) for the period 2014-2020 (second pillar of the CAP), funded by the European Agricultural Fund for Rural Development. As a priority, the state stimulates the sustainable development of agriculture, which is also promoted with national resources - through transitional national aid schemes, complementing the support with European funds under the First Pillar of the CAP and state aid. In total for the programming period 2014-2020, the country is expected to absorb about 7.5 billion euros in the agricultural sector.

Support for vulnerable and priority sectors through the implementation of coupled support schemes is also important. Bulgaria has notified the maximum eligible amount of coupled support for the period 2015 - 2020 $15 \%$ of the financial ceiling for direct payments, incl. $13 \%$ for the Livestock and Fruit and Vegetables sectors and 2\% for protein crops. Targeted support for certain sectors and industries will also be provided 
from the national budget through state aid schemes and transitional national aid. For 2020 a total budget under these schemes is envisaged in the amount of BGN 300.4 million.

The priorities and objectives of the policy in the agricultural sector, the measures and actions for their achievement in 2020 are in accordance with the Management Program of the Government of the Republic of Bulgaria for the period 2017-2021 and the National Development Program: Bulgaria 2020 (1). From the above five policy priorities in the agricultural sector, measures and actions to achieve them in 2020, it is clear that the first, second and fifth priorities are particularly important for the support of small and medium-sized farmers (Figure 6).

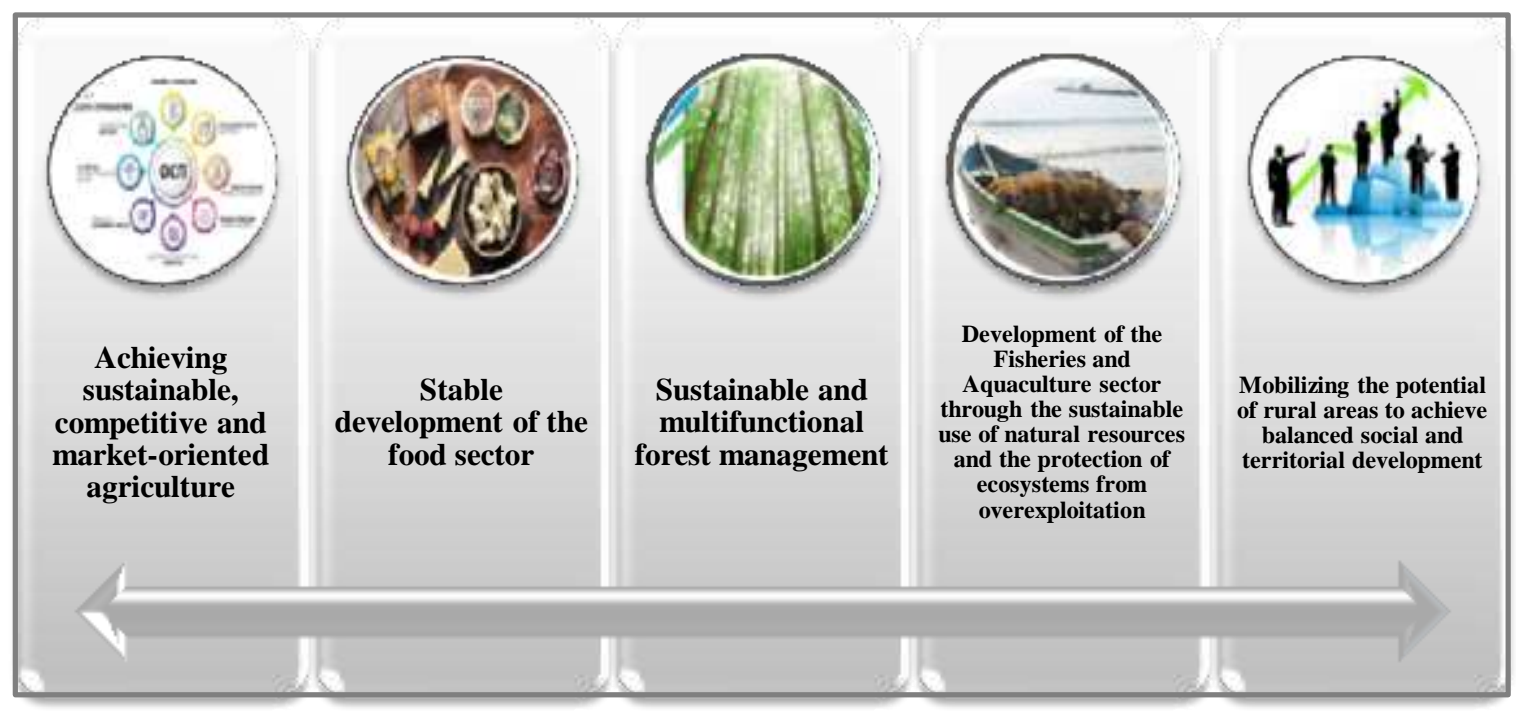

Figure 6. Policy priorities in the agricultural sector in 2020

Source: Author's figure based on data from the Agrarian Report, 2019 - MAFF

The goal of "providing financial support with a focus on small and medium-sized enterprises and stimulating profitable agricultural production and market equality" is very strong in the first priority, as well as the continuation of balanced and diversified agriculture policies. The second priority focuses on the stable development of the food sector, by ensuring the quality and safety of food and sustainable market development of farmers, which is stated in the objectives. Diversification of the rural economy and high employment of the local population, as well as improving the quality of life in rural areas are key objectives in the fifth priority.

The state national policy for increasing the competitiveness of small and family farms is also reflected in a number of other initiatives:

- publishing a list of Bulgarian producers and processing companies that trade online;

- the creation of regional "short channels" for supply in the retail chains by virtue of a special decree (decree 70 / 14.04.2020);

- national information and educational campaign "I CHOOSE 380" (13);

- additional funds for emergencies.
The Bulgarian Food Safety Agency (BFSA) has published a list of Bulgarian producers and processing companies that trade online. The initiative aims to facilitate consumers by enabling direct delivery of fresh Bulgarian products to the address. All agricultural producers and processors included in the list have the required registrations under the Food Act (FFA), where applicable - under the Veterinary Activity Act (FDA) and the Plant Protection Act (FPA). The initiative is open for registration of new producers and processors. So far, four main lists have been published:

$\checkmark$ direct deliveries of small quantities of raw materials and food of animal origin (14.5.2020);

$\checkmark$ processing plants for raw materials of animal origin (2.6.2020);

$\checkmark$ producers and traders of fruits and vegetables (16.6.2020);

$\checkmark$ producers and traders with sowing and planting material (20.5.2020).

The current pandemic conditions are a signal that we must be extremely flexible and able to work in conditions of constant and not always predictable changes. This is especially true for 
small farmers who find it difficult to sell in this emergency - closed markets, restrictions, etc. The creation of regional "short channels" for supply in retail chains is a natural necessity in emergency conditions and a need to ensure the survival of domestic producers in the regional scope. Through the intervention of the state tools, it was given the opportunity for delivery in the trade chains by virtue of a special decree (Decree №70 / 14.04.2020 (14), amended by Decree №87 of 30.04.2020) (15), which obligatorily differentiate places where are offered: milk and dairy products from Bulgarian raw milk; fish and fish products; fresh meat of large and small ruminants and eggs, honey; fresh seasonal fruits and vegetables, as well as other food products produced by regional producers. The points of sale should have an area sufficient for the display and sale of the foodstuffs concerned, and should be marked in an appropriate way to show that the products offered are regionally produced.

The launch of a national information and educational campaign "CHOOSE 380" in the week before Easter (2020) is aimed at motivating Bulgarian consumers to choose local products. This concept is "under the magnifying glass" and "in daylight" in more and more European countries, as well as in many parts of the world. In times of crisis, consumer patriotism is possible not only to help but also to save small farms from bankruptcy. On the other hand, the Bulgarian producer will be stimulated to introduce innovations, to increase the efficiency of specific productions, as well as to offer quality Bulgarian products, the Bulgarian economy in the conditions of the growing crisis in connection with COVID-19.

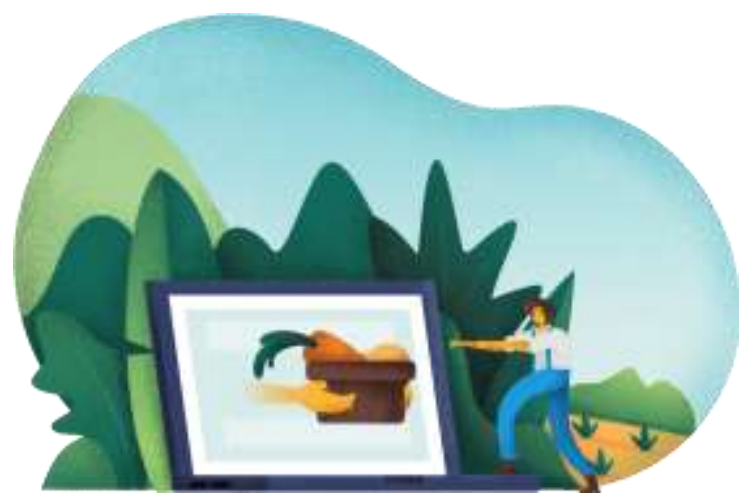

Figure 7. Logo of the initiative "I choose 380", initiated by the Association of Agricultural Producers in Bulgaria and agrozona.bg

The main goal of the campaign is to involve more organizations, partners and public figures to support and promote the idea. The expectations are to support the Bulgarian economy in the conditions of the growing crisis, as well as lasting and sustainable support for the Bulgarian agricultural production.

In the current year, in order to overcome the difficulties of unsold production in the conditions of emergency (COVID-19) at the initiative of Bulgaria, supported in the course of the negotiation process by all EU member states, additional funds are allocated for the affected sectors under three sub-measures under (16):

- farmers applying for support under direct payment schemes and measures in
Campaign 2019 and Campaign 2020 (for fruit and vegetable producers, rose

production, wine grapes, farmers, farm animals and beekeepers);

- farmers for the introduction of antiepidemic measures within agricultural holdings (farmers engaged in pig, poultry and other crops);

- compensation of small and medium enterprises for processing of agricultural products.

The extraordinary assistance COVID-19 for support of the Agriculture sector under the sub-measures has been discussed by the Ministry of Agriculture and Food with the branch organizations and the funds from approved farmers are to be used. 
Approaches to reducing the problems in agriculture are related to a targeted policy to support the development of small and mediumsized farms in traditional agricultural sectors at national and regional level. In order to realize the opportunities for multiplied benefits (strengthening market positions, building partnerships, horizontal and vertical cooperation) in each region, specific forms of cooperation between farms, local authorities and communities must be found. The initiative must come "from the inside out", i.e. business organizations to focus on consumers, market demand and market diversification of manufactured products.

\section{CONCLUSIONS}

In the conditions of a dynamic and transforming economy and constantly changing business environment, the family business is constantly changing its priorities in its development. The flexibility and sustainability of these farms is an important condition for successful marketing of the products. The role of small and family farms in Bulgaria in the sale of products of high quality and high nutritional value is undoubtedly important, especially in the regional scope. Their potential is largely untapped due to a number of concomitant problems. Adapting them to modern conditions is an important part of the ability to be competitive, to attract investment, to modernize and diversify their activities. The direction of their development is largely towards the local markets, as a result of which they are part of the regional fluctuations. The market access of the predominant number of small farms is limited, and it is they who provide the variety of good quality agricultural products at affordable prices.

In the studied region (Veliko Tarnovo region) it was found that the main channels for distribution of products from small and family farms are used, and to the greatest extent the produced products are sold through direct sales and producer markets (local farmers / regional markets). ). The preferences for realization are the lowest, by offering in wholesale markets and in retail stores. The intermediate position is occupied by the realization, through online deliveries, contracts to companies / retail chains or with individuals, as well as the supply in the chains of restaurants and hotels. Successful implementation is also possible with the inclusion of good practices, such as the establishment and operation of producer organizations on a territorial / regional basis, partnership throughout the production chain and cooperation of participants for effective implementation of the products and foods offered.

The approaches for limiting the problems in the Bulgarian agricultural economy are aimed at a purposeful policy for supporting the development of the small and medium agricultural holdings at national and regional level. The state national policy for increasing the competitiveness of small and family farms must constantly follow the focus on small farmers, who find it difficult to sell products in general, and in emergency situations, such as COVID-19 - even more so. Greater support is needed more than small farms in each region.

\section{REFERENCES}

1. Nikolova, M., M. Linkova. Status and problems in the management and development of agriculture. National Economic Archives, 1, pp. 15-28, 2020.

2. Regulation (EC) $(178 / 2002$ of the European Parliament and of the Council of 28 January 2002 laying down the general principles and requirements of food law, establishing a European Food Safety Authority and laying down procedures for food safety. http://data.europa.eu/eli/reg/2002/178/oj.

3. Food Act. Prom. SG. issue 90 of 15.10.1999, last ed. and ext. SG. No. $106 /$ 21.12.2018.

4. Agrarian Reports (2007-2019), MAFF.

5. Annual report on the state and development of agriculture -2019, p. 18. ARA.

6. Ivanov, B., R. Popov, Hr. Bashev et al. Analysis of the state of agriculture and the food industry. Swot analysis. Institute of Agrarian Economics, Sofia, pp. 24-25, 33, 314-315, 375-376, 2020.

7. Nikolova, M., M. Linkova. State and problems in the management and development of agriculture. Economic Archive, 1, pp 13-26. Academic Publishing House "Tsenov" - Svishtov, 2020.

8. https://infostat.nsi.bg/infostat/pages/reports/ result.jsf;

https://www.mzh.government.bg/bg/presscenter/novini/mzhg-predlaga-razrabotvanena-tri-podmerki-po-izvn/. 
9. Council of the European Union, 2013 "Family farming - prospects in the context of globalization", 12786/13 agri 516.

10.Report of thematic working group 8 "Family farms". Family farms in Bulgaria: status, problems and prospects for development. NSM, November, p. 5, 2014.

11.Nikolova, M., M. Linkova, R. Nenova. Small and family agribusiness. Textbook, AI "Tsenov" Svishtov, pp. 6, 12. ISBN 978954-23-1588-9, 2018.

12.Nikolova, M. Relationship between the Sustainable Models of Production in Agriculture and the Challenges to Their Development in Bulgaria. Journal of Economics and Development Studies, Vol. 3 (4), pp. 57-68, 2016.

13.https://izbiram380.agrozona.bg/.
14.Decree 70/14.04.2020 for providing main groups of food, produced on the territory of the Republic of Bulgaria, in the commercial sites, representing chains of shops. Prom. $\mathrm{SG}$, issue 37 of 21.04 .2020 , in force from 21.04.2020 to 31.12.2020.

15.Decree 87/30.04.2020 amending Decree № 70 of the Council of Ministers of 2020 for providing main groups of food produced on the territory of the Republic of Bulgaria in the commercial sites, representing chains of shops. Prom. SG, issue 40 of 05.05.2020, in force since 05.05.2020.

16.16.http://www.babh.government.bg/bg/Pag e/bylgarsko_proiszodstvo/index/bylgarsko_ proiszodstvo/\%D0\%91\%D1\%8A\%D0\%BB $\% \mathrm{D} 0 \% \mathrm{~B} 3 \% \mathrm{D} 0 \% \mathrm{~B} 0 \% \mathrm{D} 1 \% 80 \% \mathrm{D} 1 \% 81 \% \mathrm{D}$ 0\%BA\%D0\%BE\%20\%EF\%BF\%BD. 